\title{
Nachtrag und Korrektur
}

zu A. Kotthaus "Hoplostethus islandicus nov. spec. aus den südisländischen Gewässern“, Helgol. Wiss. Meeresunters., IV, 11952.

Nachtrag.

A. Der Holotypus von Hoplostethus islandicus nov. spec. befindet sich im Museum des Hamburger Zoologischen Staatsinstituts und ist dort unter der Nummer 1952/1 registriert. Eine spezielle Diagnose dieses Tieres ist zur Veröffentlichung im "Zoologischen Anzeiger" vorgesehen.

B. Nach Abschluß der oben genannten Arbeit sind noch die beiden folgenden Funde von Hoplostethus islandicus bekanntgeworden:

1. 21. 12. 1951, Island-NW, Vikural, $66^{\circ} 23^{\prime} \mathrm{N}, 25^{\circ} 38^{\prime} \mathrm{W}$, ca. 200 Meter Wassertiefe, 1 Exemplar von $59 \mathrm{~cm}$ Totallänge, gefangen von dem Bremerhavener Fischdampfer "Skolpenbank", Kapt. U. ERNST.

2. 3. 1. 1952, Island-NW, am Steilhang der sog. "Vikuralbank“, $66^{\circ} 02^{\prime} \mathrm{N}$, $27^{\circ} 00^{\prime} \mathrm{W}, 350-360$ Meter Wassertiefe, 1 Exemplar von $59 \mathrm{~cm}$ Totallänge, gefangen von dem Bremerhavener Fischdampfer „Venus“, Kapt. A. Gulbis.

Korrektur.

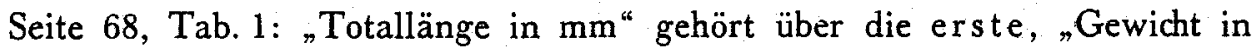
Gramm" über die $z$ we ite Zahlenkolonne.

Seite 75, 76 und 86: Die Formel für die Caudalflosse ist voll mit arabischen Zahlen zu schreiben, also etwa 8/18/7 und nicht VIII/18/VII; denn trotz des stachelstrahligen Charakters der Randstrahlen der Caudale handelt es sich um echte Gliederstrahlen. 